\title{
Organizing on two wheels: uncovering the organizational patterns of Hells Angels MC in Sweden
}

\author{
Amir Rostami ${ }^{1}$ (D) Hernan Mondani $^{1}$
}

Published online: 24 May 2017

(C) The Author(s) 2017. This article is an open access publication

\begin{abstract}
During the last decades, Outlaw Motorcycle Clubs (OMCs) have become a concern for crime prevention and law enforcement agencies. The general perception of OMCs is ambiguous. They are seen either as highly structured criminal organizations whose members use their motorcycle clubs for conducting sophisticated criminal enterprises, or as clubs built around the camaraderie of freedom-seeking bikers. Using unique Swedish longitudinal data on gang membership and co-offending patterns, we study the organizational dynamics of Hells Angels MC Sweden and its sub-organizations Red \& White Crew and Red Devils MC. Our results reveal a complex picture. Co-offending network patterns and offense type distributions vary for each sub-organization, indicating potential differences in organizational dynamics. Red \& White Crew has features that are more similar to street gangs than OMCs, and Red Devils $\mathrm{MC}$ has a more decentralized and chapter-based pattern of criminal collaboration than Hells Angels MC. Besides increasing our understanding of OMC collaboration structure, our results have implications for crime prevention strategies. We suggest that social responses and law enforcement efforts should take into account the heterogeneity of OMCs in order to avoid counterproductive consequences in terms of increased group cohesiveness.
\end{abstract}

Keywords Outlaw motorcycle gangs · Organized crime $\cdot$ Hells angels $\cdot$ Red Devils $\cdot$ Red $\&$ white crew $\cdot$ Social network analysis $\cdot$ Criminal organizing $\cdot$ Outlaw bikers

Amir Rostami

amir.rostami@sociology.su.se

1 Institute for Futures Studies and Department of Sociology, Stockholm University, 106 91 Stockholm, Sweden 


\section{Introduction}

\section{Outlaw motorcycle clubs}

Outlaw Motorcycle Clubs (OMCs), or Outlaw Motorcycle gangs (OMGs) as law enforcement agencies tend to call them, are a subculture rooted in the immediate post-World War II era (Harris 2016). The term denotes a subculture comprising organizations that bring together and organize motorcycle riders into clubs with distinctive and recognizable value system, set of principles, symbols and paraphernalia embracing a certain law-breaking character (Lauchs et al. 2015; Quinn and Shane Koch 2003, 2010).

Among OMCs, the big four organizations that stand out are Hells Angels, Bandidos, Outlaws, and Pagans. These are the largest both in terms of international expansion and membership (Barker 2014; NGIC 2015). The big four and other transnational OMCs pose serious concerns to law enforcement agencies around the world.

The US Federal Bureau of Investigations (FBI) describes OMCs as a 'serious national domestic threat' (NGIC 2009: 9) and the European Union's law enforcement agency Europol has developed a project called Monitor to prevent and combat the criminal activities of OMCs in Europe, since they consider OMCs to be an emerging organized crime threat to European internal security (Europol 2010).

The FBI's National Gang Intelligence Center (NGIC) ${ }^{1}$ - which is comprised of representatives from US law enforcement agencies combating organized crime and gangs - describes OMCs as highly structured criminal organizations whose members engage in criminal activities such as violent crime, weapons trafficking, and drug trafficking, and whose members use their motorcycle clubs as conduits for criminal enterprises (NGIC 2015:8). Europol has a similar description of OMCs, describing them as 'extremely hierarchical' and 'uncompromising' homogenous criminal gangs involved in crime (Europol 2015). McIntosh (2010) has argued that from relatively humble beginnings, outlaw motorcycle gangs, such as the Hells Angels, Outlaws, Bandidos, and others have evolved into sophisticated organized crime syndicates responsible for a large proportion of the global illicit drug and weapons trades.

However, as Barker (2014) has suggested, any discussion on OMCs begins with the central question of their fundamental nature. Are OMCs a group of individuals organized around the love for motorcycles in certain clubs, and that happen to have members who break the law (like other social organizations such as the police), or are OMCs criminal gangs whose members ride motorcycles and are organized and devoted to crime for profit (e.g., Barger et al. 2000, 2003; Barker 2014:1)? In Sweden, even a political party, Frihetspartiet (Liberty Party), has been created to mobilize against the use of the label of "gangs".

\footnotetext{
${ }^{1}$ The NGIC is comprised of representatives from the Federal Bureau of Investigation (FBI); US Drug Enforcement Administration (DEA); US Bureau of Alcohol, Tobacco, Firearms, and Explosives (ATF); US Bureau of Prisons (BOP); United States Marshals Service (USMS); US Immigration and Customs Enforcement (ICE); US Department of Defense (DOD); and CBP (NGIC 2013).

${ }^{2}$ Interview with the leader of the Frihetspartiet published in Dagens Juridik 2010-03-18. "It's amazingly convenient to terrorize bikers" http:/www.dagensjuridik.se/2010/03/frihetspartiet-det-ar-himla-praktiskt-attterrorisera-hojfolk
} 
Most of the OMCs have similar organizational rules and structures, usually with elected officers for designated roles such as president, vice president, treasurer, road captain, and sergeant-at-arms (Lauchs et al. 2015). Harris (2016) argues that these clubs provided opportunities for their members to oppose mainstream establishments, which were perceived as suppressing their individuality (Harris 2016:74). The post-war re-established camaraderie also explains the militaristic organizational design of OMCs, with officers, sergeants-at-arms and other symbols and paraphernalia which uphold the subculture of OMCs. And this gateway from social malaise may also explain the commonality between OMCs and religious sects that Watson (1982) found in his study such as extreme in orientation and separation from the mainstream community through in- and out-group distinction.

The members of these organizations tout the outlaw lifestyle as an image: in this view, each member and chapter is voluntary organized and locally self-ruled, with a high level of democratic decision-making, with members living 'beyond' the law as freedom-loving chivalrous rebels. In other words, they do not represent themselves as criminal enterprises or gangs. For example, the Hells Angels (HAMC) leader Sonny Barger argues that HAMC consists of "a group of complete individuals [and] the only thing we [HAMC] agree on is our love for the club [...]" (Barger et al. 2003:286) and he continues: "Where's the connection with the Hell's Angels as a criminal organization? There was no proof it was part of club policy" (Barger et al. 2000:396).

While, it is generally recognized that criminality is a significant aspect of the OMCs milieu (Richardson 1991; Quinn and Forsyth 2009; Quinn and Shane Koch 2003) and are classified as a form of organized crime (Abadinsky 2012), there are different views on how this criminality can best be described. Quinn and Shane Koch (2003) describes this duality as two accounts: OMC crimes are described as either "quite lacking in finesse and even antithetical to the welfare of a sophisticated syndicate" or "as sophisticated international crime syndicates operation in a rationally calculated manner akin to that of traditional organized crime syndicates" (Quinn and Shane Koch 2003:294). In their attempt to explore the nature of criminality within OMCs, Qiunn and Koch (2003:296) outlined four distinct types of offenses that can be observed within these groups: 1) spontaneous expressive acts (one or a few members involved in violent crimes, such as bar fights, directed at rivals or other actors from within the saloon society milieu); 2) planned expressive acts (violent crime committed against adversaries and reflecting the priorities of the club); 3) short-term instrumental acts (exploiting an opportunity to meet a goal for at least one member such as theft); and 4) ongoing instrumental enterprises (planned criminal activities involving one or more cliques such as drug production and distribution).

One organization in particular stands out by virtue of its size and notoriety: The Hells Angels Motorcycle Club (HAMC). It is established in around 56 countries spanning five continents and may have as many as 5000 members divided into more than 400 chapters (Hells Angels Motorcycle Corporation 2017; NGIC 2015; Rikskriminalpolisen 2012b). ${ }^{3}$ Because of its size, history, organization, and strong brand, HAMC is category-defining for clubs within the outlaw sphere and the organizational design of other OMCs is based on the original HAMCs guide (Lauchs et al. 2015). HAMC is not only category-defining for other OMCs; they have also served as a role model for other types of gangs, such as Swedish street-gangs (Rostami 2013).

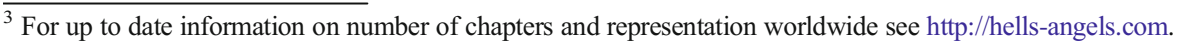


HAMC has created serious concerns for American, European and Swedish law enforcement agencies (Europol 2010, 2015; NGIC 2011, 2013, 2015; Rikskriminalpolisen 2012a, 2012b).

In this study, we try to reach a better understanding of the organizational and collaboration patterns of HAMC in Sweden and its sub-organizations Red \& White Crew (RWC) and Red Devils MC (RDMC), and through this vertical comparison get insights into the organization of the HAMC sphere in Sweden. We do this by investigating the patterns of criminal collaboration in co-offending relations and criminal offenses.

\section{Hells Angels MC Sweden: History and organization}

During the past seventy years, HAMC has developed from a minor club in Fontana, California to an international organization established in 56 countries with thousands of members (Hells Angels Motorcycle Corporation 2017; Hells Angels Motorcycle Corporation 2017; NGIC 2015; Rikskriminalpolisen 2012b). Among Outlaw biker organizations, HAMC stands out both as a pioneer in branding and global expansion and in many countries, such as in Sweden, where they have had a hegemonic position among other OMCs and gangs (Rostami 2013, 2016).

The first footsteps in Europe took place in Great Britain in 1969 and the first Scandinavian HAMC chapter was established in 1980 when the outlaw biker club The Union became a HAMC chapter in Denmark (Pedersen and Lindstad 2012). Sweden was next in line when the Dirty Dräggels become the first HAMC hangaround chapter 1991, becoming the first HAMC chapter in Sweden in 1993 (Larsson and Wierup 2011). Today, HAMC Sweden consists of 14 chapters.

Even though Sweden has traditionally had a biker culture, the Swedish biker culture has been strongly influenced by the developments in the US (Grundvall 2005; Lagergren 1999). From privileged entertainment for the upper class in the early 1900s to transportation for the working class in the 1920s, a peculiar biker subculture developed in the 1940s and later. Similar to developments in the US, Swedish biker culture was strongly influenced by media culture (Grundvall 2005; Lagergren 1999). At the end of the 1960s and the 1970s, Swedish outlaw culture took off, according to Grundvall (2005) and Fredelius (1978), strongly influenced by the motion picture The Wild One (1967). Several outlaw biker clubs were created, such as Peking Outlaws (1967), Hising Island Free MC (1967), Flying Riders (1969) Mothers Freak MC (1971) Mandroms MC (1971), Kvillebäcken MC (1972), Lunden MC (1972), and Vikings (1973).

With the expansion of the Swedish biker culture, violent conflicts arose between motorcycle clubs. As problems proliferated, the authorities began to take an interest in the clubs (Grundvall 2005). However, during the 1980s - both in Sweden and Denmark-violent conflicts between different outlaw clubs reached a new level, and the larger international outlaw organizations such as HAMC and Bandidos entered the Scandinavian scene.

Because of external circumstances, survival, adaptation, members' attitudes and background, a normative active resistance against authority, and the legitimacy of legally offensive behavior developed. Clubs in conflict, as in the case of Denmark and Sweden, frequently sought protection in larger international outlaw clubs such as Hells Angels and Bandidos, resulting in conflictual formations affecting recruitment of 
members and club identity. Recurrent conflict was also why supporter clubs were formed with the objective of creating a defense force and ultimately securing the organization's growth and survival. This was the case with the AK81 in Denmark and Red \& White Crew in Sweden.

The development of the Swedish biker milieu is characterized by merging and segmentation. Before the introduction of Hells Angels and Bandidos the Swedish OMCs consisted of locally bounded single chapters which later merged into the Hells Angels and Bandidos during the 1990s. In the early 2000s new OMCs emerged such as Outlaw MC, Mongols MC and later the Satudarah MC, and challenged previously dominating clubs, resulting in a segmented biker landscape and an increased need of allocated other biker clubs for recruitment of new members both from within the biker milieu and non-bikers. Hells Angels through its "Sverigemodellen" and Bandidos through its "Independent Motorcycle Association" (I.M.A) have sought to organize biker clubs who do not belong to any fraction but accept being under the influence of either Hells Angels MC or Bandidos MC (Rikskriminalpolisen 2012b, 2015). Simultaneously new supporter and satellite clubs were recruited, both traditional OMCs and "street-OMCs" such as Red \& White Crew, X-Team and AK81 ${ }^{4}$ which seem to be a crossover between street-gangs and OMCs.

The Red \& White Crew (RWC) came to the attention of the Danish police in 1999. It was established as a counterpart to Bandidos' X-Team and was later reorganized under the name AK81 in Denmark, while RWC continued to be used in Sweden. In 2000, the Swedish RWC, which at the time was operating under the name of Red \& White Support Crew, came to the attention of Swedish police. Today RWC has 13 chapters in Sweden. The first three were formed in 2001 and the rest from 2006 onwards. RWC is not a traditional biker club; in fact, they do not have the basic recruitment procedure of other biker clubs, such as having access to a motorcycle. In their organizational bylaws, they even state that ' $R$ \& W Crew is part of the structure of HAMC Sweden and not a club on its own. All R \& W Crew chapters are tied to and controlled by a HAMC chapter. In addition, each RWC member is dedicated to and controlled by a designated member of the HAMC, who is titled the 'crew manager' (Red and White Crew 2009; Red Devils 2003).

The RWC does not have a formal hierarchy structure aside from two levels of affiliation, full membership and those who have applied for membership. The latter cannot participate in internal meetings of the organization and thus have a lower status than full members. To become a member one must be male, at least 18 years, recommended by other members of RWC and be approved by HAMC (Red and White Crew 2009).

In fact, RWC shows similarities with Swedish street gangs. They have similar attributes such as gang sweatshirts instead of biker vests and have a more flexible recruitment process. However, they still have formal rules similar to a biker club, such as i) meeting procedures, ii) voting processes with a 'one member one vote'-system, iii) an exclusion mechanism e.g. removing gang tattoos when leaving the organization. The RWC seems to constitute a type of stormtrooper role for HAMC, while at the same time

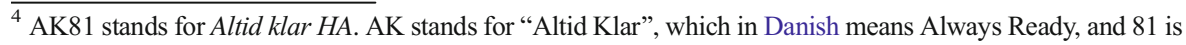
synonymous with the letters HA meaning Hells Angels.
} 
enjoying the privilege of using the strong brand of HAMC for its own activities (Red and White Crew 2009).

In contrast to RWC, Red Devils MC (RDMC) is a motorcycle club with an organizational structure and rules based on the original Hells Angels' guide. It was established in 2001 in Sweden as an official supporter club to HAMC. Red Devils MC has 8 chapters in Sweden. The HAMC has the right to decide on new members and supporter club chapters. All members must own a Harley-Davidson motorcycle, must pledge full loyalty to $\mathrm{HAMC}$, and each chapter must have at least five members. Full members in RDMC are not allowed to seek membership in any other organization except HAMC. In contrast to both RWC and HAMC, which are represented in larger cities as well as larger towns, RDMC is mainly based in larger towns (Red Devils 2003; Sverigemodellen 2011).

\section{Aim of this study}

In this study, we analyze the Hells Angels MC (HAMC) sphere in Sweden. We do so by vertically comparing members of full chapters (HAMC) with members of its suborganizations Red \& White Crew (RWC) and Red Devils MC (RDMC). Our analyses are based on unique Swedish co-offending data from the Swedish National Council for Crime Prevention and gang membership data from the Swedish Police. We analyze the organizational patterns with the help of social network analysis, a powerful tool that has been previously applied to understanding criminal collaboration and organizational dynamics in general (Everton 2012), and Hells Angels in particular (Morselli 2009a, b).

\section{Data and methods}

\section{Data sources}

Four primary methods of data collection are typically used in organized crime research: interviews, non-participatory field observations, content analysis of official documents such as police records and intelligence files, and quantitative studies of official crime data (Hobbs and Antonopoulos 2014; von Lampe 2016a).

Each set of data collection techniques has its own distinct advantages and entails different methodological challenges. This study is no exception. It is based on the Swedish criminal register of suspected offenders (misstankeregistret) from 1995 to 2012 , containing information on all suspected crimes and offenders (6.7 million registered offences by 1.25 million individuals) and the Swedish gang database members of different what are considered organized crime groups such as HAMC Sweden, which in total comprises 3426 individuals in 145 sub-groups. These two registries were matched to produce a unique database of criminal organization and cooffending from 1995 to 2012. Crime network datasets of co-offending by members of HAMC Sweden, RWC and RD were extracted from this database.

Information on group affiliation in our database is based on law enforcement data built on an intelligence confirmation process. The different information sources are verified through various channels, such as informants, undercover police, surveillance teams, telephone intercepts, open and other technical sources, or by eyewitness testimony from police officers. 
This type of data in general and data for crime networks in particular have limitations. One limitation is that the interaction between law enforcement and the observed population affects the network structure and dynamics. For example, arrests, incapacitation, or intelligence leaks can have an effect on patterns of relationships in a crime network, and this affects the patterns we measure and visualize through network analysis tools. There are a number of other limitations and biases in crime network data in general, and police-collected gang membership data suffers from various selection biases. For example, reliance on official co-offending data often misses data. This means that many offences that are not reported are not included in the data. For further discussion, see Rostami and Mondani (2015). Despite these challenges and limitations, it is quite common for researchers to use data gathered from law enforcement agencies, particularly in the study of organized crime. In fact, much of our knowledge about criminal collaboration is based on law enforcement data (e.g., Block and Block 1993; Cressey 1969; Decker and Pyrooz 2015:4; Lombardo 2012).

Our sample for this study consists of three subsets centered around the three suborganizations: Hells Angels MC, Red \& White Crew and Red Devils MC. The HAMC dataset contains information on 2537 cases of suspected offences, 1142 individuals and 6523 registered offences. Out of the 14 HAMC chapters that exist today, 12 appear in the data. The RWC dataset has 3289 cases comprising 1527 individuals and 7548 registered suspected offences. Finally, the RDMC dataset has 749 cases, 339 individuals and 1554 suspected offences.

\section{Social network analysis}

Recently, social network analysis (SNA) has received increasing attention as a tool for the study of criminal networks (Masys 2014). Social network analysis has traditionally concerned itself with the descriptions and models of social entities and their interactions (Wasserman and Faust 1994). Continuing along this research tradition, the pioneering works by Morselli (2009b), McGloin (2005) and Sarnecki (2001) formally introduced SNA as a method for the analysis of criminal collaboration. Later on, SNA tools were gradually applied to a wider selection of crime-related phenomena besides cooffending, such as organized crime, extremism, cybercrime (Morselli 2014), and disruption of hidden networks (Everton 2012), to name a few examples. Talking specifically about Hells Angels, Morselli (2009a) observed in his study of HAMC in Quebec that there is a widespread criminal market involving HAMC. He argued that despite the law enforcement perception of HAMC as a hierarchical, monopolistic organization controlling criminal markets, the criminal activities of the organization do not directly follow from its formal organizational structure.

Social network analysis is about the study of patterns of relations (links) between entities (nodes). Nodes and links can represent many different things, from friendship relations between individuals to transmission of diseases across countries. In our case, we use SNA to represent one aspect of criminal collaboration patterns, namely the co-offending structure. Nodes are individuals suspected of criminal activities, and every time they are registered in a case together, they get joined by a reciprocal link that is commonly referred to as an edge. Aggregating the information over time spans a co-offending network.

Our network analyses comprise three distinct sub-organizations: HAMC, RWC, and RDMC. For each case, we look at the network formed by the group members and their 
co-offenders. For instance, we take all of the people registered as members of RWC in the Swedish Gang Database and look at the cases in the offence registry that involve these individuals. The one-mode network is then constructed case-wise, where individuals are linked if they are suspected of a crime in the same case. The three resulting networks will then overlap partially, but they will also be different in as much as they are centered in the particular group they are constructed from. In a first stage of analysis, reported in this paper, we pool all offences in the period together and look at the static co-offending network pattern. We use the co-offending network as a proxy for organizational structure and collaboration patterns. We use the free software gephi for network visualization, ${ }^{5}$ and we compute the network measures with the free package networkx (Hagberg et al. 2008), a python package for the analysis of complex networks. ${ }^{6}$

\section{Results}

\section{Co-offending network patterns}

Our unique data allow us to make a vertical comparison between criminal collaboration patterns of HAMC and its sub-organizations RWC and RDMC. The member composition of each co-offending network-HAMC, RWC and RDMC-is shown in Table 1. It is important to note that almost all the members in these organizations have been suspected for criminal offences (95\% in the case of HAMC, 97\% for RWC and $85 \%$ for $\mathrm{RDMC}$ ). The first thing we notice is that the three networks are of rather different size. The network of HAMC members and their co-offenders comprise 1142 individuals; the network of RWC members, 1527 individuals; and the Red Devils network, 339 individuals. The majority of co-offenders are registered as not belonging to any group; this is a known fact about gangs (Klein and Maxson 2006), and is especially the case for RWC, but less so for RDMC.

Not surprisingly, the second largest group fraction in each network corresponds to the group these individuals can over time be reached - directly or indirectly - by any other individual in the component by means of a criminal collaboration. The giant component is much larger than the others, as the size of the second largest component is only $9 \%$ of the largest. This giant component features different kinds of network configurations. On the one hand, there are cliques where a network is built around, such as HAMC for the HAMC network. However, the proportion is much higher for RDMC (almost 30\%) and is lowest for RWC (under 10\%). The prevalence of the other groups in a network centered on a given group is roughly constant. Thus, for example, Red \& White affiliates amount to around $3.2 \%$ of the individuals in the HAMC and RDMC networks. The fractions of individuals belonging to another MC gang is large only in the case of HAMC, while both HAMC and RWC are linked with over $1 \%$ of individuals from other criminal groups, such as football hooligans (these are relatively small figures though).

Until now we have looked at the group composition for each network. But how about the connectivity of the co-offending patterns in each case? In Fig. 1 we can see

\footnotetext{
5 Available online at: https://gephi.org/.

${ }^{6}$ Available online at: http://networkx.github.io/index.html.
} 
Table 1 Group composition for each co-offending network. Number of individuals (nodes in the network) belonging to a given group in a network

\begin{tabular}{|c|c|c|c|}
\hline Group & $\begin{array}{l}\text { Hells Angels } \\
\text { MC network }\end{array}$ & $\begin{array}{l}\text { Red \& White } \\
\text { Crew network }\end{array}$ & $\begin{array}{l}\text { Red Devils } \\
\text { MC network }\end{array}$ \\
\hline Hells Angels MC & $180(15.8 \%)$ & $45(2.9 \%)$ & $12(3.5 \%)$ \\
\hline Red \& White Crew & $37(3.2 \%)$ & $142(9.3 \%)$ & $11(3.2 \%)$ \\
\hline Red Devils & $9(0.8 \%)$ & $10(0.7 \%)$ & $92(27.1 \%)$ \\
\hline Other Outlaw Motorcycle Gangs & $18(1.6 \%)$ & $6(0.4 \%)$ & $1(0.3 \%)$ \\
\hline Other criminal groups & $13(1.1 \%)$ & $23(1.5 \%)$ & $1(0.3 \%)$ \\
\hline Other co-offenders, non-members & $885(77.5 \%)$ & $1301(85.2 \%)$ & $222(65.5 \%)$ \\
\hline Total & $1142(100.0 \%)$ & $1527(100.0 \%)$ & $339(100.0 \%)$ \\
\hline
\end{tabular}

the three co-offending networks. A summary of network properties for each case is presented in Table 2.

The three networks look qualitatively very different. The HAMC network (Fig.1, upper panel) is quite interconnected, with clusters where each individual is connected to everyone else (so-called cliques) and star-like configurations. The RWC network (Fig.1, middle panel) has a few larger cliques and is overall less interconnected than the HAMC network, while the RDMC network (Fig.1, lower panel) features lots of small isolated configurations.

Quantitatively speaking, in the case of the HAMC network, over $60 \%$ of the individuals and $70 \%$ of the co-offending edges are part of a giant component, meaning that all of these individuals can over time be reached-directly or indirectly-by any other individual in the component by means of a criminal collaboration. The giant component is much larger than the others, as the size of the second largest component is only $9 \%$ of the largest. This giant component features different kinds of network configurations. On the one hand, there are cliques in which each individual is directly linked to the others, and which correspond to single large cases. One of the cliques, which we call Case 1, involves 1 individual among whom there are members from the three MC gangs. Case 1, therefore, appears in all three co-offending networks. We do not want our results to be biased by this single event, so we show our analyses both with and without this case (see Table 2).

The other 73 components in the HAMC network consist either of isolated HAMC members, that is, individuals suspected for an offence alone, and star-like configurations, mostly with non-members corresponding to a succession of different collaborations. The presence of RWC members is restricted to the giant component and a couple of other minor components, and RDMC members appear in a clique in the giant component and otherwise also a couple of times in smaller components. The RWC co-offending network is larger in terms of nodes but also disproportionately larger in terms of co-offending edges. This is above all due to the presence of more of the abovementioned cliques. A group of them is even disconnected from the giant component (270 nodes, to the right in the figure, second largest component at $34 \%$ the size of the giant) and thus the giant component contains only $27 \%$ of the total number of edges. The other 59 components are qualitatively similar to the HAMC case. Finally, the 


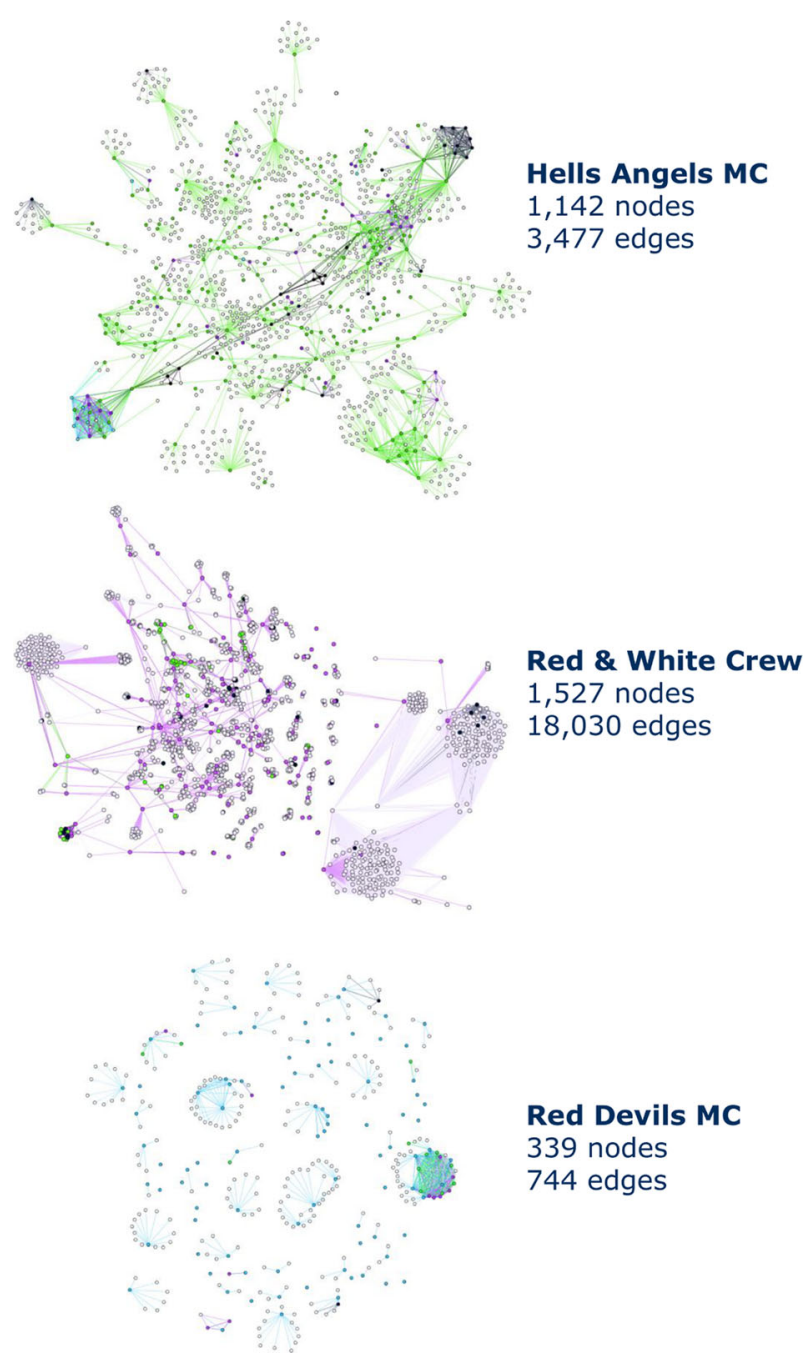

Fig. 1 The three co-offending networks. Cumulated offences for the period 1990-2011. Two nodes representing individuals are linked by an edge when those individuals are suspected of an offence in the same case. Edge width proportional to number of offences. Node Color by group membership: green: Hells Angels MC, violet: Red \& White Crew, cyan: Red Devils, black: other groups, white: non-members. Edge color merges colors of connecting nodes

RDMC co-offending network is considerably smaller and more fragmented than the other two networks. The giant component only comprises about $12 \%$ of the individuals, and the second largest is $78 \%$ the size of the giant, meaning the RDMC network is considerably more decentralized than the others. The other components are essentially either isolated individuals or very small configurations (51 out of 76 components have three individuals or less).

But the size of the giant component and the number of its co-offending edges is not all there is to it. It is also important to describe how clustered the component is, the presence of shortcuts and triangles. A first approximation is density, which is simply 
Table 2 Summary of network properties for each co-offending network

\begin{tabular}{llll}
\hline Network measure & $\begin{array}{l}\text { Hells Angels } \\
\text { MC network }\end{array}$ & $\begin{array}{l}\text { Red \& White } \\
\text { Crew network }\end{array}$ & $\begin{array}{l}\text { Red Devils } \\
\text { MCtwork }\end{array}$ \\
\hline Number of nodes & 1142 & 1527 & 339 \\
Number of edges & 3477 & 18,030 & 744 \\
Number of components & 74 & 60 & 76 \\
Giant component: number of nodes & $707(61.9 \%)$ & $788(51.6 \%)$ & $41(12.1 \%)$ \\
Ratio size second largest component/ size giant component & 0.09 & 0.34 & 0.78 \\
Giant component: number of edges & $2437(70.1 \%)$ & $4862(27.0 \%)$ & $242(32.5 \%)$ \\
Giant component: density & 0.0098 & 0.0157 & 0.2951 \\
[same measure excluding Case 1] & {$[0.0095]$} & {$[0.0162]$} & {$[0.0867]$} \\
Giant component: diameter & 16 & 20 & 3 \\
[same measure excluding Case 1] & {$[16]$} & {$[17]$} & {$[6]$} \\
Giant component: average clustering coefficient & 0.7413 & 0.7529 & 0.7218 \\
[same measure excluding Case 1] & {$[0.7344]$} & {$[0.7493]$} & {$[0.4581]$} \\
\hline
\end{tabular}

the number of edges as a fraction of all the possible number of edges. This measure depends on the network size, and consequently networks of different sizes cannot be compared by density. However, we can still look at each density value individually, and immediately realize that the RDMC giant component is very dense, but most of its edges actually drop out when we consider Case 1.

On the other hand, the diameter is the maximum shortest path between two nodes in the component. The larger the diameter, the fewer shortcuts in the network component and the costlier it can be to communicate or reach every individual. The HAMC network has a diameter of 16 , and this value does not change when we remove Case 1 , indicating that there are plenty of other co-offending edges in the rest of the component to compensate for this lack. The diameter of the RWC network is higher than in the HAMC network, even though the networks have comparable sizes, so cooffending patterns in RWC are sparser and have fewer shortcuts than in HAMC. The value actually drops when removing Case 1, which means that this case sits at the periphery of this network component. In the case of the RDMC network, the smaller isolated components translate into smaller diameter, and actually doubles when controlling for Case 1, showing that this giant component has a core around this case.

A last measure of clustering in the collaboration pattern is the number of triangles in the network. The clustering coefficient shows the fraction of a node's co-offenders that are themselves linked through criminal collaboration. Interestingly, the average clustering coefficient is essentially the same for all three networks, around 0.7 (a high value, mostly a consequence of the presence of collaboration cliques). When controlling for Case 1, it drops marginally for the first two networks but substantially for the RDMC network, in line with our previous observations.

Collaboration is coupled to membership, and in this final stage of the network analysis we look at co-offending edges and inter-group dynamics, a unique feature of this dataset. From Table 3 we see that edges linking full members within HAMC, RWC and RDMC respectively, constitute only a small fraction of the total number of edges (as observed before, most collaborations involve non-members). However, out of those 
Table 3 Summary of network-based collaboration measures

\begin{tabular}{|c|c|c|c|}
\hline Collaboration measure & $\begin{array}{l}\text { Hells Angels } \\
\text { MC network }\end{array}$ & $\begin{array}{l}\text { Red \& White } \\
\text { Crew network }\end{array}$ & $\begin{array}{l}\text { Red Devils } \\
\text { MC network }\end{array}$ \\
\hline Edges involving at least one full member [a] & $\begin{array}{l}1516 \\
(43.6 \%)\end{array}$ & $\begin{array}{l}1724 \\
(9.6 \%)\end{array}$ & $\begin{array}{l}379 \\
(50.9 \%)\end{array}$ \\
\hline $\begin{array}{l}\text { Edges between full members [b] } \\
\text { (as fraction of }[\mathbf{a}] \text { ) }\end{array}$ & $\begin{array}{l}200 \\
(13.2 \%)\end{array}$ & $\begin{array}{l}86 \\
(5.0 \%)\end{array}$ & $\begin{array}{l}30 \\
(7.9 \%)\end{array}$ \\
\hline $\begin{array}{l}\text { Edges between full members in same chapter } \\
\text { (as fraction of [b]) }\end{array}$ & $\begin{array}{l}148 \\
(74.0 \%)\end{array}$ & $\begin{array}{l}67 \\
(77.9 \%)\end{array}$ & $\begin{array}{l}30 \\
(100.0 \%)\end{array}$ \\
\hline
\end{tabular}

co-offending edges, a small proportion takes place between members of the same group. This fraction is highest for the HAMC network (13.2\%); it is 5\% for the RWC and $7.9 \%$ for RDMC. When we consider how many of those edges are between members of the same chapter, in the HAMC network $74 \%$ of the intra-group edges happen within the same chapter, meaning that HAMC is locally based when it comes to full members, but still able to collaborate between chapters on a country-wide level. RWC has a comparable fraction (77.9\%), and RDMC has the highest (100\%), thus being very local and more chapter-based than HAMC and RWC. ${ }^{7}$

\section{Offence-type patterns}

The fact that a number of individuals are linked by their criminal collaborations and the characterization of those network patterns is in itself interesting. But it is still an open question whether the offence profile of these three groups differs or not. The offence type distributions are shown in Fig. 2. Looking at the total of offences (Fig.2, left panel) we can see that HAMC and RWC tend to have similar offence types; particularly prevalent are "Alcohol, Drugs and Firearms," "Theft and Robbery," and "Assault." HAMC members and co-offenders more frequently engaged in "White Collar Crime." "Homicide" and "Trafficking, Rape and Other Sexual Offences" are the least frequent types of offences. But naturally, the statistical pattern we observe is at least partially due to the differences in the size of the networks and the number of full members in each group. If we normalize the sum of offences by the number of nodes in the network (cf. Table 2), we obtain the distributions in Fig. 2, center panel. ${ }^{8}$ Now the patterns are more similar across criminal groups, although "White Collar Crime" is still disproportionately more prevalent among HAMC members

\footnotetext{
${ }^{7}$ Our analyses measure aggregated patterns of collaboration. The question may arise as to what extent our results are the consequence of the long period of time taken in the data. To control for that effect, we made a sensitivity analysis considering only the co-offending collaborations for the period 2008-2012, i.e. the last 5 years of data. Our observed collaborations exhibit a similar pattern as the one reported in the main text. Indeed, HAMC members account for $20.8 \%$ of the total edges and within-chapter edges are $78.9 \%$ of that number. For the case of RWC the figures are $8.1 \%$ within members and $70.2 \%$ of them within chapters. Finally, for RDMC $10.0 \%$ of the edges are collaborations between full members, and $100.0 \%$ of those within the same chapter.

${ }^{8}$ Offences per node multiplies by a factor of 10 . The conclusions we draw are not affected by this factor; it is done to make the scales consistent.
} 


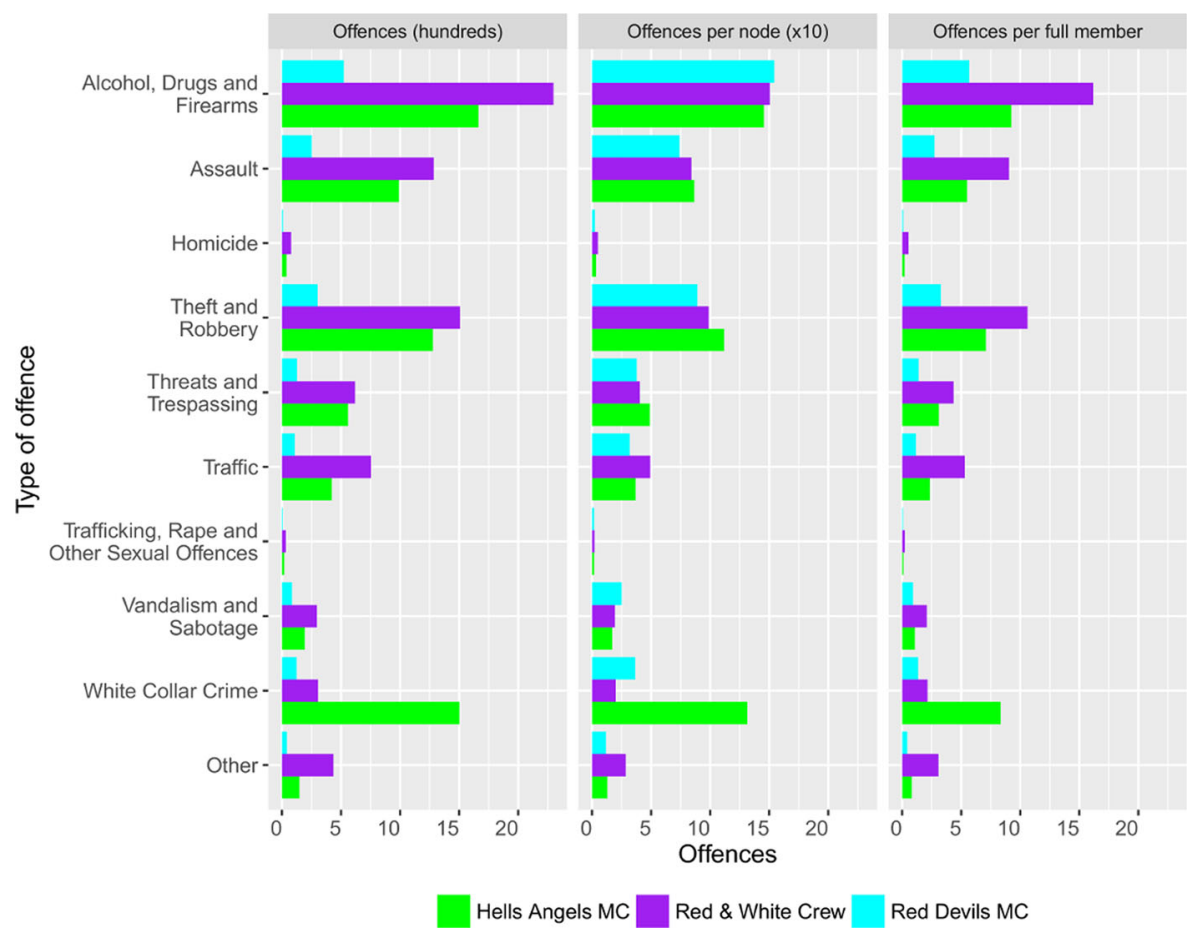

Fig. 2 Offence type distribution, by co-offending network and normalization type: total, per network node and per full member

and co-offenders. The same distribution, but now normalized by the number of full members in each group (cf. Table 1), is seen in Fig. 2, right panel. This pattern is qualitatively much closer to the totals we saw in the left panel. Another interesting finding is that RWC is predominantly active in types of offences that are often associated with less sophisticated organizations, such as street gangs, like "Alcohol, Drugs and Firearms," "Assault," and "Theft and Robbery," while they are less active in "White Collar Crime," which either requires access to legal structures or specific know-how.

The RDMC shows the lowest offence frequencies in terms of both absolute number of offences and offences per full member. But when normalizing by network size, some offence types exhibit higher frequencies for RDMC, namely "Alcohol, Drugs and Firearms" and "Vandalism and Sabotage." These categories are coupled to the stereotypical picture of an outlaw biker club involved in drugs and vandalism. Additionally, the RDMC comes second in "White Collar Crime," a type that is associated with a certain kind of organizational maturity. We should keep in mind that this result is valid when we take into account the whole network and not just full members. ${ }^{9}$

\footnotetext{
${ }^{9}$ One additional interpretation for the diversity in observed offense type patterns could be the age structure of the sub-organizations. We checked for that by looking at the age distribution for offenses during the year 2012. We find that the age distributions are roughly the same for the Hells Angels full members in the Hells Angels network (mean 39.8 years, standard deviation 8.8) and Red Devils full members in the Red Devils network 38.8 (9.5) years, while full RWC members in the RWC network are younger: 28.8 (6.8) years.
} 
To conclude, the RWC exhibits a criminal activity pattern in categories that traditionally require a low degree of organizing, such as traffic offences and street-oriented crimes types like assault and drugs. The HAMC has a criminal pattern with a high level of criminal activity in all categories, especially white collar crime. The RDMC seems to be an intermediate case between the criminal patterns of the HAMC and RWC, characterized by a diverse pattern of criminal activities.

\section{Discussion}

There are several thousand clubs around the world and they are far from a homogeneous milieu with each club having its distinctive profile, which in turn influences recruitment of members and its activities (Quinn and Shane Koch 2003; Wolf 1991). With the help of unique Swedish data on co-offending and gang membership, we are able to vertically compare HAMC and its sub-organizations. Our analyses reveal a complex picture, where the organizations under study exhibit qualitatively different patterns. We can be sure of one thing: criminal activity is a central part of the careers of the members in these organizations, a finding that is in line with previous research (Quinn and Shane Koch 2003). In the case of HAMC and RWC, over 95\% of full members have been suspected for crimes, and RDMC is slightly behind with $85 \%$.

While our three organizations have a somewhat similar formal organizational design, they exhibit very different organizational patterns, both in terms of the composition of their co-offending networks, their connectivity, and the distributions of offence types. This is in line with what Morselli (2009a) found for Hells Angels in Canada.

The HAMC has a more cohesive co-offending pattern, as evidenced by the larger relative size of the giant component and the relatively low network diameter. This means that while the organization has clear affiliation boundaries, the dynamics of criminal collaboration between members is more flexible than in the other sub-organizations. Around $15.2 \%$ of the collaboration edges involving a HAMC member occur in-house; this is twice as much as in the RDMC case (8.6\%), and approximately three times higher than for RWC (5.3\%). This may explain why the offence type distributions for HAMC feature a higher proportion of more sophisticated offence types. This higher level of in-house collaboration may reduce exposure of the crime activities in the organization and thereby reduce the risk of law enforcement interventions, giving the organization the opportunity to further develop and mature.

The co-offending pattern of RWC we observe gives indications of a loosely connected organization. While, the RWC stipulates in its bylaws that a RWC chapter must serve under a designated HAMC chapter and every member needs to be affiliated with a full member in HAMC, there seems to be a low level $(2.9 \%)$ of criminal collaboration in terms of the relative fractions of members in these organizations. For example, there is a slightly higher level $(3.5 \%)$ of criminal collaboration between the RWC and HAMC. Looking at the offence-type pattern, we find that RWC members are active predominantly in offences like "Alcohol, Drugs and Firearms," "Assault," and "Theft and Robbery." The pattern of low-level co-offending between the RWC and HAMC, organizationally exclusive cohesion between chapters of the RWC and HAMC, together with predominantly street-oriented offences, shows that the RWC is 
mainly a less organized gang that performs tasks for respective HAMC chapter as a satellite club. This conclusion is in line with the law enforcement conception that RWC members serve as storm troopers for the HAMC with the responsibility of taking active role in conflicts, extortion, and other kinds of criminal activities, while at the same time taking advantage of the HAMC brand.

The RDMC co-offending network is considerably smaller, more fragmented $(12.1 \%$ of the nodes in the giant component), and more bent inwards than the other two cooffending networks. Around $27 \%$ of the individuals in the RDMC network are full members, a higher fraction than in the HAMC (15.8\%) and RWC (9.3\%). Additionally, the RDMC exhibits a higher proportion of collaboration within the same chapter; as a matter of fact, all criminal collaboration between full members in the RDMC is chapterbased. This indicates that the RDMC is a locally-based and decentralized organization. This may explain the offence type distribution, having a mixture of sophisticated offence types (like white collar crime) and street-oriented criminality (such as vandalism and drugs). We performed a sensitivity analysis by restricting the observations to the period 2008-2012 and the results hold for that case as well.

The differential collaboration patterns that we observe can be interpreted in different ways. It may be that the three organizations are specialized in mutually interacting parts of a larger organizational system, with a division of labor materialized in differentiated functions: the RWC acts as stormtroopers, the RDMC acts as seed-bed for potential organizational growth of the HAMC, and the HAMC members themselves act as an overarching, privileged, organized community. Alternatively, they can be interpreted as a product of the development of OMCs within a commonly shared value system, in an ecology of organizations operating in a specific environment in a time-geographical context.

These findings are important not only for an organizational understanding of OMCs, but for crime prevention strategies as well. Problem identification and understanding of this phenomenon is crucial in terms of social responses and policing, since flawed analyses can result in misguided and counterproductive actions and initiatives (e.g., Goldstein 1990; Klein and Maxson 2006).

To take one example, if OMCs are treated as homogenous organizations with similar stages of organizational maturity, there is a risk that social responses and policing only increase the group's cohesiveness and identity, resulting in isolation from the community and strengthening intragroup behavior as the only pattern of reference. This would further complicate society's collective action against OMC criminal activities. Therefore, policing strategies should take into account the social dynamics of each chapter (see Harris 2016).

At the same time, we are aware that every set of empirical data has its limitations. For instance, our data does not capture the coexistence of various types of social relations (like kinship, friendship, being victim of a crime) as part of associational structures and motives for action like entrepreneurship. Moreover, we cannot discuss the internal hierarchical structure of positions in these organizations as constituent of their degree of formalization (for further discussion of these dimensions, see von Lampe 2016a, b). Additionally, our data are valid for the understanding of HAMC sphere in the Swedish context, and further research is needed to examine the validity in other contexts.

Another suggestion for future research could be to focus less on formal aspects of organization and more on the underlying patterns of relations and collaborations and 
interaction between criminal organizations, and to go beyond the club-level description into the web of relationships that members are embedded in, as well as the positions they occupy in various organizations, as our study shows most criminal relationships take place outside the sphere of the organization. In this context, social network analysis can be a powerful analytical toolbox to get new insights into organizational dynamics.

\section{Compliance with ethical standards}

Funding This study was funded by Riksbankens Jubileumsfond P11-0866:1 and Myndigheten för Samhällsskydd och Beredskap 2016-486 and 2016-7045.

Ethical approval All procedures performed in studies involving human participants were in accordance with the ethical standards of the institutional and/or national research committee and with the 1964 Helsinki declaration and its later amendments or comparable ethical standards.

Informed consent Informed consent was obtained from all individual participants included in the study.

Ethical approval This article does not contain any studies with animals performed by any of the authors.

Open Access This article is distributed under the terms of the Creative Commons Attribution 4.0 International License (http://creativecommons.org/licenses/by/4.0/), which permits unrestricted use, distribution, and reproduction in any medium, provided you give appropriate credit to the original author(s) and the source, provide a link to the Creative Commons license, and indicate if changes were made.

\section{References}

Abadinsky H (2012) Organized crime, 10th edn. Wadsworth Publishing, Belmont, CA

Barger RS, Zimmerman K, Zimmerman K (2000) Hell's angel: the life and times of Sonny Barger and the Hell's angels motorcycle Club. Four Estate, London

Barger RS, Zimmerman K, Zimmerman K (2003) Ridin' high, Livin' free: Hell-raising motorcycle stories. Perennial, New York, N.Y

Barker T (2014) Outlaw motorcycle gangs as organized crime groups. Springer, Cham

Block, Carolyn Rebecca and Richard Block (1993) Street Gang Crime in Chicago. Washington, D.C: U.S. Department of Justice Office of Justice Programs

Cressey DR (1969) Theft of a nation: the structure and operations of organized crime in America. Harper and Row, New York, NY

Decker SH, Pyrooz DC (2015) The handbook of gangs. John Wiley \& Sons

Europol (2010) OC-SCAN policy brief for threat notice. Europol, Hague

Europol (2015) "EU Policy Cycle - EMPACT." EMPACT. Retrieved December 17, 2015 from: (https://www. europol.europa.eu/content/eu-policy-cycle-empact)

Everton SF (2012) Disrupting dark networks. Cambridge University Press

Fredelius, Erik (1978) “1978: 1.” RIG-Kulturhistorisk Tidskrift 61(1). Retrieved September 30, 2016 from: (http://pjos.org/index.php/rig/article/download/8431/7568)

Goldstein H (1990) Problem-oriented policing. McGraw-Hill, New York

Grundvall S (2005) Vagabond MC: Gemenskap, Manlighet Och Marginalitet : En Studie Av En Västsvensk Bikerklubb. Institutionen för socialt arbete, Göteborgs universitet, Göteborg

Hagberg, Aric, Daniel Schult, and Pieter Swart (2008) "Exploring Network Structure, Dynamics, and Function Using NetworkX." Retrieved August 16, 2016 from: (http://conference.scipy. org/proceedings/scipy2008/paper_2/)

Harris KJ (2016) The fierce commitment to $1 \%$ motorcycle clubs. Journal of Policing, Intelligence and Counter Terrorism 11:73-83 
Hells Angels Motorcycle Corporation (2017) "Charters Worldwide." Hells-Angels.com. Retrieved April 14, 2017 from: (http://affa.hells-angels.com/charters/)

Hobbs D, Antonopoulos GA (2014) How to Reserach organized crime. In: Paoli L (ed) The Oxford handbook of organized crime, the Oxford handbooks in criminology and criminal justice. Oxford University Press, New York, N.Y

Klein MW, Maxson CL (2006) Street gang patterns and policies. Oxford University Press, Oxford

Lagergren L (1999) Svensk Motorcykelkultur. Institute of Tema Research, Linköping University, Linköping, $\mathrm{PhD}$-dissertation

Larsson M, Wierup L (2011) Svensk maffia: en kartläggning av de kriminella gängen. Norstedts, Stockholm Lauchs M, Bain A, Bell P (2015) Outlaw motorcycle gangs. Palgrave Macmillan UK, London

Lombardo RM (2012) Organized crime in Chicago: beyond the mafia. University of Illinois Press

Masys AJ (ed) (2014) Networks and network analysis for Defence and security. Springer International Publishing, Cham

McGloin J (2005) Policy and intervention considerations of a network analysis of street gangs. Criminology \& Public Policy 4(3):607-635

McIntosh CN (2010) Alex Caine, the fat Mexican: the bloody rise of the Bandidos motorcycle Club. Trends in Organized Crime 13(2-3):254-256

Morselli C (2009a) Hells Angels in Springtime. Trends in Organized Crime 12(2):145-158

Morselli C (2009b) Inside criminal networks. Springer New York, New York, NY

Morselli, Carlo (2014) Crime and Networks

NGIC (2009) National Gang Threat Assessment 2009. US Dept of Justice, National Gang Intelligence Center, Washington, D.C.

NGIC (2011) National Gang Threat Assessment 2011 - Emerging Trends. Washington, D.C: US Dept of justice, National Gang Intelligence Center

NGIC (2013) 2013 National Gang Report. National Gang Intelligence Center, Washington, DC

NGIC (2015) 2015 National Gang Report. National Gang Intelligence Center, Washington, DC

Pedersen, Maria and Jonas Markus Lindstad (2012) "The Danish Gang-Joining Project: Methodological Issues and Preliminary Results." in Youth Gangs in International Perspective: Results from the Eurogang program of research. New York, N.Y.: Springer

Quinn JF, Forsyth CJ (2009) Leathers and Rolexs: the symbolism and values of the motorcycle Club. Deviant Behavior 30:235-265

Quinn J, Shane Koch D (2003) The nature of criminality within one-percent motorcycle clubs. Deviant Behavior 24:281-305

Red and White Crew (2009) "Stadgar 'Bylaws."

Red Devils MC (2003) "Stadgar 'Bylaws."”

Richardson A (1991) Outlaw motorcycle gangs: USA overview. Department of Justice, Bureau of Organized Crime and Criminal Intelligence, Sacramento, CA

Rikskriminalpolisen (2012a) Konfliktsituationen hells angels MC och Outlaws MC. Rikskriminalpolisen, Stockholm

Rikskriminalpolisen (2012b) Rapport hells angels MC och red and white crew. Rikskriminalpolisen, Stockholm

Rikskriminalpolisen (2015) Rapport Bandidos MC. Rikskriminalpolisen, Stockholm

Rostami A (2013) Tusen fiender: En studie om de svenska gatugängen och dess ledare. Linnéuniversitetet, Växjö

Rostami A (2016) Criminal organizing: studies in sociology of organized crime. Stockholm University, Stockholm, PhD-dissertation

Rostami A, Mondani H (2015) The complexity of crime network data: a case study of its consequences for crime control and the study of networks. PLoS One 10(3):e0119309

Sarnecki J (2001) Delinquent networks: youth co-offending in Stockholm. Cambridge University Press

Sverigemodellen (2011) "Stadgar 'Bylaws.' Sverigemodellen

von Lampe K (2016a) Organized crime: analyzing illegal activities, criminal structures, and extra-legal governance. SAGE Publications, US

von Lampe K (2016b) The ties that bind: a taxonomy of associational criminal structures. In: Antonopoulos GA (ed) Illegal entrepreneurship, organized crime and social control. Springer International Publishing, Cham

Wasserman S, Faust K (1994) Social network analysis: methods and applications. Cambridge University Press Watson JM (1982) Righteousness on two wheels: bikers as a secular sect. Sociol Spectr 2:333-349

Wolf DR (1991) The rebels: a Brotherhood of Outlaw Bikers. University of Toronto Press 